\title{
Interactions between Thiourea and Imines. Prelude to Catalysis
}

\author{
Vincent de Paul N. Nziko and Steve Scheiner* \\ Department of Chemistry and Biochemistry, Utah State University, Logan, Utah 84322-0300, United States
}

\section{Supporting Information}

ABSTRACT: The interaction between thiourea and a series of imines was examined via high-level $\mathrm{ab}$ initio calculations. For each imine, there is a set of stable complexes that represent minima on the potential energy surface. One type is characterized by a pair of symmetric $\mathrm{NH} \cdots \mathrm{N}$ hydrogen bonds (HBs), with both $\mathrm{NH}$ groups of thiourea approaching the imine $\mathrm{N}$ from above and below its molecular plane. Another geometry category combines a linear $\mathrm{NH} \cdots \mathrm{N}$ with a $\mathrm{CH} \cdots \mathrm{S} \mathrm{HB}$. A third, which is less stable, has the $\mathrm{S}$ approaching the imine's $\mathrm{CH}_{2}$ group, and a stacking arrangement is present in the fourth. Interaction energies vary from $\sim 2 \mathrm{kcal} / \mathrm{mol}$ to a maximum of $13.5 \mathrm{kcal} / \mathrm{mol}$. The formation of the complex tends to elongate the $\mathrm{C}-\mathrm{N}$ bond within the imine by as much as $0.004 \AA$, but there are certain dimers that cause a small contraction of this bond.

\section{INTRODUCTION}

Organocatalysis refers to the efficient use of small organic molecules containing no metallic atoms as catalysts for various asymmetric organic reactions. These catalysts have several advantages: they are environmentally friendly, cheap, insensitive to moisture, and considerably less toxic and can control the chirality of the product. ${ }^{1-4}$ A common mode of organocatalysis takes advantage ${ }^{5}$ of iminium ion activation, enamine activation, and activation via hydrogen bonding.

Thiourea and its derivatives have emerged ${ }^{6,7}$ as a very powerful class of organocatalysts in part because of their ability to form strong hydrogen bonds (HBs). The first asymmetric hydrocyanation of imines ${ }^{7}$ was accomplished with the use of a thiourea-derived catalyst. The proposed reaction mechanism proceeds through the formation of a thiourea/imine hydrogenbonded reactant complex. Thiourea derivatives have been used as catalysts for a number of reactions, ${ }^{8-12}$ including the azaBaylis-Hillman reaction, Strecker reaction, Mannich reaction, and Pictet-Spengler reaction. All these reactions make use of imines as a reagent that forms complexes with the thiourea derivative.

There is unfortunately a dearth of current information about the details of the complexes formed by thiourea with imines. It is not certain, for example, whether thiourea engages in HBs with the imine, and if so whether it serves as proton donor or acceptor. There is also the possibility that it could act as both simultaneously, i.e., $\mathrm{NH}_{2}$ groups as the donor and $\mathrm{S}$ as the acceptor. However, there is no limitation that the intermolecular interactions must be HBs. The $S$ atom has shown a propensity ${ }^{13-28}$ to engage in chalcogen bonds, which would involve the $\mathrm{S}$ and $\mathrm{N}$ of the imine in a direct attraction, with no need for a bridging $\mathrm{H}$ atom. Still another sort of interaction would involve the $\pi$-systems of the two molecules in a stacked arrangement. At issue also is the way in which the complexation affects the imine. Does the interaction serve as a prelude to catalysis in some way, facilitating the entire process?

This work is designed to provide answers to some of these questions via quantum chemical calculations that can focus on the fundamentals of the complexation process. It is possible to determine which types of complexes might be formed upon the approach of the thiourea to the imine. The various sorts of dimers can be examined to see which are most favorable, what types of noncovalent bonds they contain, and how the interaction affects the molecular properties of each system. The prototypical imine investigated here is $\mathrm{CH}_{2} \mathrm{NH}$. The study broadens the scope from a standard imine to related systems, as well, which may serve catalytic functions. Oximes are imines in which the imino hydrogen is replaced by a hydroxyl group, which is modeled here by $\mathrm{CH}_{2} \mathrm{NOH}$. Replacement with an amino leads to the hydrazone class, with $\mathrm{CH}_{2} \mathrm{NNH}_{2}$ as the prototype. In carbimidates, a hydroxyl group is located on the imine carbon, which is modeled here by $\mathrm{NHCHOH}$. Each of these molecules was paired with thiourea, to identify the sorts of complexes in which they can engage, and to analyze the properties of each.

\section{COMPUTATIONAL METHOD}

The quantum mechanical calculations were conducted using GAUSSIAN 09. ${ }^{29}$ Second-order Møller-Plesset perturbation theory (MP2) was used to include the effects of electron correlation. Geometries were optimized in the framework of Dunning's augmented correlation consistent polarized valence double- $\zeta$ basis set (aug-cc-pVDZ). Frequency calculations confirmed that the complexes obtained correspond to true minima. The interaction energies, $E_{\text {int }}$, were evaluated as the difference between the energy of the complex and the sum of the energies of the two monomers, using their geometries within the optimized complex. $E_{\text {int }}$ was corrected for basis set superposition error via the counterpoise ${ }^{30}$ procedure.

Higher-level calculations with larger basis sets made use of the MP2/aug-cc-pVDZ geometries. The interaction energies were extrapolated to the complete basis set (CBS) by a methodology used by us ${ }^{19}$ in our earlier work. The

Received: August 25, 2015 


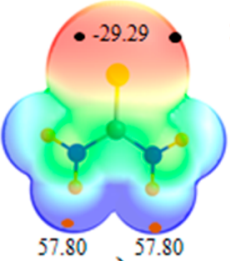

a)

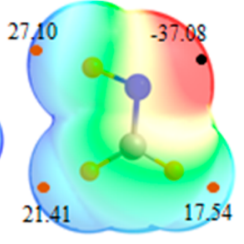

b)

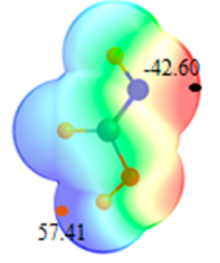

c)

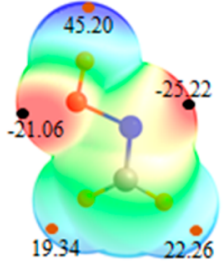

d)

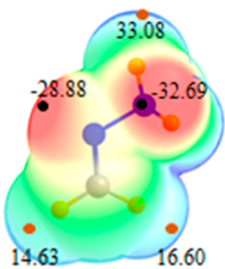

e)

Figure 1. Molecular electrostatic potentials (MEPs) of (a) thiourea, (b) $\mathrm{CH}_{2} \mathrm{NH}$, (c) $\mathrm{NHCHOH},(\mathrm{d}) \mathrm{CH}_{2} \mathrm{NOH}_{\text {, and }}(\mathrm{e}) \mathrm{CH}_{2} \mathrm{NNH}_{2}$, all on a surface corresponding to 1.5 times the vdW radii. Colors vary from -0.04 au (red) to +0.04 au (blue). Red and black spheres indicate positions of $V_{\mathrm{s}, \max }$ and $V_{\mathrm{s}, \min }$, respectively, in units of kilocalories per mole.

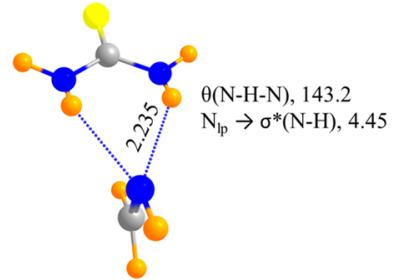

A1, 9.66

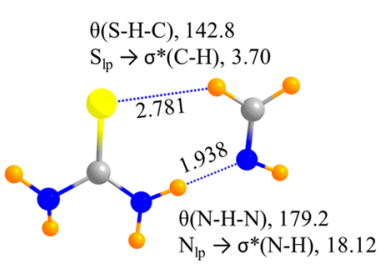

A2, 9.65

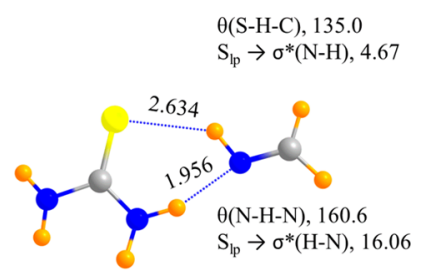

A3, 9.17

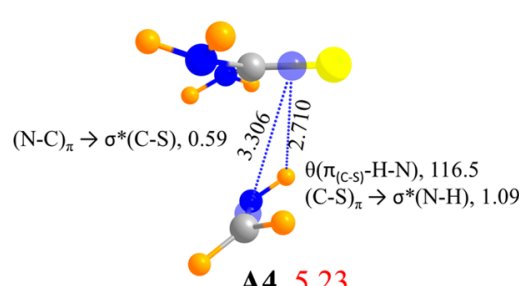

A4, 5.23

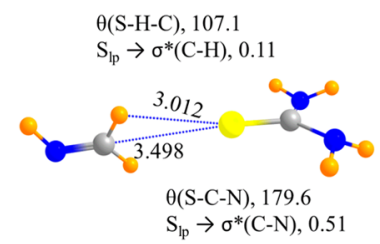

A5, 1.90

Figure 2. Optimized geometries of complexes of thiourea with $\mathrm{CH}_{2} \mathrm{NH}$. The red number refers to the interaction energy (kilocalories per mole) evaluated at the $\operatorname{CCSD}(\mathrm{T}) / \mathrm{CBS}$ level. Distances are in angstroms and angles in degrees. The NBO value of $E(2)$ is in kilocalories per mole.

extrapolation is based on the idea ${ }^{31}$ that correlation energy is roughly proportional to $X^{-3}$ for basis sets of the aug-cc-pVXZ type. It utilizes a two-step method, described by eq 1 , with triple and quadruple sets: ${ }^{32}$

$$
\Delta E_{\mathrm{MP} 2 / \mathrm{CBS}}=\left(64 \Delta E_{\mathrm{MP} 2 / \text { aug-cc-pVQZ }}-27 \Delta E_{\mathrm{MP} 2 / \text { aug-cc-pVTZ }}\right)
$$

A correction was added via eq 2 to account for discrepancies between MP2 and $\operatorname{CCSD}(\mathrm{T})$

$$
\begin{aligned}
E_{\mathrm{CCSD}(\mathrm{T}) / \mathrm{CBS}}= & E_{\mathrm{MP} 2 / \mathrm{CBS}}+\left[E_{\mathrm{CCSD}(\mathrm{T}) / \mathrm{aug}-\mathrm{cc}-\mathrm{pVDZ})}\right. \\
& \left.-E_{\mathrm{MP} 2 / \mathrm{aug}-\mathrm{cc}-\mathrm{pVDZ}}\right]
\end{aligned}
$$

The molecular electrostatic potential (MEP) was evaluated for the monomers in their optimized geometry at the MP2/ aug-cc-pVDZ level. Electron density shifts caused by complexation were calculated as the difference between the electron density of the complex and the sum of those of the monomers, again in the geometry within the complex. The total interaction energy was dissected into various components by symmetryadapted perturbation theory (SAPT) analysis ${ }^{33,34}$ using MOLPRO, ${ }^{35}$ at the HF/aug-cc-pVDZ level of theory. Natural bond orbital (NBO) formalism ${ }^{36,37}$ provided information about interorbital charge transfer, evaluated at the M06-2X/aug-ccpVDZ level to include correlation effects. The electron density was analyzed through the atoms in molecule (AIM) procedure $^{38,39}$ to determine the position of the bond critical points, as well as the density and its Laplacian using the AIMALL software, ${ }^{40}$ at the MP2/aug-cc-pVDZ level.

\section{RESULTS}

Monomers. The MEP of each monomer is illustrated in Figure 1, where red and blue regions indicate negative and positive regions, respectively. The MEP of thiourea is negative at the $S$ atom, particularly along its lone pair direction, with a $V_{\mathrm{s} \text {,min }}$ of $-29.3 \mathrm{kcal} / \mathrm{mol}$. The most positive regions correspond to extensions of the $\mathrm{NH}$ bonds, rising up to a maximum of $+57.8 \mathrm{kcal} / \mathrm{mol}$ for the $\mathrm{H}$ atoms anti to the $\mathrm{C}=\mathrm{S}$ bond.

The potentials surrounding the imine molecules have certain features in common. All exhibit a negative region along the $\mathrm{N}$ lone pair, with the potential varying from a minimum of -25.2 $\mathrm{kcal} / \mathrm{mol}$ for $\mathrm{CH}_{2} \mathrm{NOH}$ to a maximum of $-42.6 \mathrm{kcal} / \mathrm{mol}$ for $\mathrm{NHCHOH}$. Another minimum occurs near the $\mathrm{O}$ or $\mathrm{N}$ atom of the substituted imines. In the case of $\mathrm{CH}_{2} \mathrm{NNH}_{2}, V_{\mathrm{s} \text {,min }}$ on the $\mathrm{NH}_{2}$ group slightly exceeds that on the imine $\mathrm{N}$ atom. Positive regions are associated with the various $\mathrm{H}$ atoms, most notable the $\mathrm{OH}$ group with a $V_{\mathrm{s}, \max }$ of $45-57 \mathrm{kcal} / \mathrm{mol}$; least positive are the $\mathrm{CH}$ protons.

Heterodimers. The 1:1 complexes between thiourea and each of the imines were searched for all minima, using their MEPs as a starting point, and supplemented by optimizations of randomly generated starting configurations. The searches led to a total of 19 dimers, illustrated in Figures 2-5. The interaction energy of each is displayed, along with salient geometric properties. 
Table 1. Electron Densities $\left(10^{-2} \mathrm{au}\right)$ at the Indicated AIM Bond Critical Point

\begin{tabular}{|c|c|c|c|c|c|c|c|c|c|c|c|}
\hline \multirow[t]{2}{*}{ A1 } & $\mathrm{NH} \cdots \mathrm{N}$ & 1.66 & B1 & $\mathrm{OH} \cdots \mathrm{S}$ & 2.98 & $\mathrm{C} 1$ & $\mathrm{NH} \cdots \mathrm{N}$ & 3.04 & D1 & $\mathrm{NH} \cdots \mathrm{N}$ & 2.08 \\
\hline & $\mathrm{NH} \cdots \mathrm{N}$ & 1.66 & & $\mathrm{NH} \cdots \mathrm{O}$ & 2.50 & & $\mathrm{OH} \cdots \mathrm{S}$ & 2.74 & & $\mathrm{NH} \cdots \mathrm{N}$ & 1.97 \\
\hline \multirow[t]{2}{*}{$\mathrm{A} 2$} & $\mathrm{NH} \cdots \mathrm{N}$ & 2.97 & B2 & $\mathrm{NH} \cdots \mathrm{N}$ & 2.21 & $\mathrm{C} 2$ & $\mathrm{NH} \cdots \mathrm{N}$ & 2.34 & D2 & $\mathrm{NH} \cdots \mathrm{N}$ & 1.66 \\
\hline & $\mathrm{OH} \cdots \mathrm{S}$ & 1.06 & & $\mathrm{NH} \cdots \mathrm{O}$ & 1.36 & & $\mathrm{CH} \cdots \mathrm{S}$ & 1.07 & & $\mathrm{NH} \cdots \mathrm{N}$ & 1.58 \\
\hline \multirow[t]{2}{*}{ A3 } & $\mathrm{NH} \cdots \mathrm{N}$ & 2.74 & B3 & $\mathrm{NH} \cdots \mathrm{N}$ & 2.76 & C3 & $\mathrm{NH} \cdots \mathrm{N}$ & 1.78 & D3 & $\mathrm{NH} \cdots \mathrm{N}$ & 2.94 \\
\hline & $\mathrm{NH} \cdots \mathrm{S}$ & 1.36 & & $\mathrm{NH} \cdots \mathrm{S}$ & 1.44 & & $\mathrm{NH} \cdots \mathrm{N}$ & 1.04 & & $\mathrm{CH} \cdots \mathrm{O}$ & 1.05 \\
\hline \multirow[t]{2}{*}{ A4 } & $\mathrm{NH} \cdots \mathrm{S}$ & 0.95 & B4 & $\mathrm{C} \cdots \mathrm{N}$ & 0.79 & $\mathrm{C} 4$ & $\mathrm{CH} \cdots \mathrm{S}$ & 0.55 & D4 & $\mathrm{NH} \cdots \mathrm{N}$ & 1.97 \\
\hline & & & & & & & & & & $\mathrm{NH} \cdots \mathrm{S}$ & 1.49 \\
\hline \multirow[t]{3}{*}{ A5 } & $\mathrm{CH} \cdots \mathrm{S}$ & 0.56 & & & & & & & D5 & $\mathrm{NH} \cdots \mathrm{N}$ & 1.24 \\
\hline & $\mathrm{CH} \cdots \mathrm{S}$ & 0.56 & & & & & & & & $\mathrm{CH} \cdots \mathrm{S}$ & 0.71 \\
\hline & & & & & & & & & D6 & $\mathrm{CH} \cdots \mathrm{S}$ & 0.59 \\
\hline
\end{tabular}

Beginning with the $\mathrm{CH}_{2} \mathrm{NH}$ dimers in Figure 2, there are two structures with equal energy. $\mathbf{A l}$ is characterized by a pair of equivalent $\mathrm{NH} \cdots \mathrm{N}$ HBs to the same imine $\mathrm{N}$ proton acceptor. Each $\mathrm{HB}$ is $2.235 \AA$ in length and is distorted by $37^{\circ}$ from linearity. The NBO value of $E(2)$ for the charge transfer from the $\mathrm{N}$ lone pair to each pertinent $\mathrm{NH} \sigma^{*}$ antibonding orbital is $4.45 \mathrm{kcal} / \mathrm{mol}$, corresponding to a $\mathrm{HB}$ of reasonable strength. This supposition is confirmed by the presence of a AIM bond path between the relevant atoms, with a $\rho$ at the bond critical point of $0.0166 \mathrm{au}$, as indicated by the first entry in Table 1 . Note that this geometry pairs together the most positive region of thiourea with a negative area of $\mathrm{CH}_{2} \mathrm{NH}$, although the two bridging protons lie above and below the plane of $\mathrm{CH}_{2} \mathrm{NH}$ and thus miss $V_{\mathrm{s} \text { min }}$.

The A2 dimer, of equivalent energy, is characterized by one linear $\mathrm{NH} \cdots \mathrm{N} \mathrm{HB}$, supplemented by a much longer and weaker $\mathrm{CH} \cdots \mathrm{S} \mathrm{HB}$. The greater strength of the former is accentuated by its length of $<2 \AA$, and a large $E(2)$ of $18 \mathrm{kcal} / \mathrm{mol}$. Its $\rho_{\mathrm{BCP}}$ is nearly 3 times that of the $\mathrm{CH} \cdots \mathrm{S} \mathrm{HB}$ and double that of the $\mathrm{NH} \cdots \mathrm{N} \mathrm{HBs}$ in A1. This bond strengthening relative to $\mathbf{A 1}$ is due in large part to the approach of the proton along the plane of $\mathrm{CH}_{2} \mathrm{NH}$, wherein lies the $\mathrm{N}$ lone pair. In terms of monomer MEPs, the $\mathrm{H}$ of thiourea that is cis to $\mathrm{S}$ is less positive than the trans $\mathrm{H}$. Likewise, the $\mathrm{CH}$ proton and the $\mathrm{S}$ exhibit extrema smaller than those of the atoms involved in the HBs of $\mathbf{A 1}$.

The $\mathrm{NH} \cdots \mathrm{N}$ HB persists in $\mathrm{A} 3$, despite a $20^{\circ}$ nonlinearity coupled with some stretching, but the $\mathrm{CH} \cdots \mathrm{S} \mathrm{HB}$ of $\mathbf{A} 2$ is replaced by a $\mathrm{NH} \cdots \mathrm{S} \mathrm{HB}$. This arrangement is slightly weaker than that in $\mathbf{A 1}$ or $\mathbf{A 2}$. It might be noted that a certain amount of cooperativity will be present in $\mathbf{A} \mathbf{2}$ and $\mathbf{A} \mathbf{3}$ as each molecule serves as both an electron donor and an electron acceptor, whereas A1 is likely weakened by negative cooperativity as the imine acts as a double electron donor.

A4 is considerably less stable. It contains a weak $\mathrm{NH} \cdots \pi \mathrm{HB}$ wherein the $\mathrm{C}=\mathrm{S} \pi$-bonding orbital serves as the electron donor. The $\mathrm{NH}$ proton lies some $2.71 \AA$ from the $\mathrm{C}=\mathrm{S}$ midpoint, as shown in Figure 2. An AIM bond path connects the $\mathrm{H}$ and $\mathrm{S}$ atoms, which might appear as a $\mathrm{NH} \cdots \mathrm{S}$ rather than a $\mathrm{NH} \cdots \pi$ HB. There is also some stabilization contributed by the interaction of the $\mathrm{CN} \pi$-bond of the imine and the CS $\sigma$ antibond of thiourea, so this minimum could perhaps best be classified as a stacked structure. (There is no corresponding AIM bond path for the latter interaction.) The weakest dimer found on the thiourea/ $\mathrm{CH}_{2} \mathrm{NH}$ PES is A5, bound by only 1.90 $\mathrm{kcal} / \mathrm{mol}$. While initial examination of the geometry might suggest a bifurcated $\mathrm{CH} \cdots \mathrm{S} \mathrm{HB}, \mathrm{NBO}$ analysis suggests rather a tetrel bond, wherein charge is transferred from the $\mathrm{S}$ lone pairs to the $\mathrm{CN} \sigma^{*}$ antibonding orbital of the imine. AIM, on the other hand, tends toward the alternate description of a symmetric bifurcated $\mathrm{CH} \cdot \cdots \mathrm{S} \mathrm{HB}$.

As reported in the first entry of Table 2, the interaction energy of $\mathbf{A 1}$ is $9.11 \mathrm{kcal} / \mathrm{mol}$ at the MP2/aug-cc-pVDZ level.

Table 2. Interaction Energies (kilocalories per mole) for Complexes of Thiourea with $\mathrm{CH}_{2} \mathrm{NH}$ Calculated with the aug-cc-pV(X)Z Basis Set

\begin{tabular}{cccccccc}
\multicolumn{9}{c}{ MP2 } & & & \multicolumn{2}{c}{$\operatorname{CCSD}(\mathrm{T})$} \\
\cline { 1 - 4 } \cline { 7 - 8 } $\mathrm{X}$ & $\mathrm{D}$ & $\mathrm{T}$ & $\mathrm{Q}$ & $\mathrm{CBS}$ & & $\mathrm{D}$ & $\mathrm{CBS}$ \\
$\mathrm{A} 1$ & 9.11 & 9.73 & 9.97 & 10.15 & & 8.62 & 9.66 \\
$\mathrm{~A} 2$ & 8.86 & 9.67 & 9.95 & 10.15 & & 8.36 & 9.65 \\
$\mathrm{~A} 3$ & 8.45 & 9.31 & 9.58 & 9.78 & & 7.84 & 9.17 \\
$\mathrm{~A} 4$ & 4.81 & 5.45 & 5.66 & 5.81 & & 4.23 & 5.23 \\
$\mathrm{~A} 5$ & 1.70 & 1.89 & 1.96 & 2.01 & & 1.59 & 1.90 \\
\hline
\end{tabular}

Enlarging the basis set leads to small progressive increments up to $9.97 \mathrm{kcal} / \mathrm{mol}$ with the quadruply polarized set. Extrapolation to a complete set results in an interaction energy higher than that of pVDZ by $1 \mathrm{kcal} / \mathrm{mol}$. Replacing the MP2 treatment of electron correlation by $\operatorname{CCSD}(\mathrm{T})$, on the other hand, reduces the interaction energy, by roughly $0.5 \mathrm{kcal} / \mathrm{mol}$ with the aug-cc-pVDZ set. Again, extrapolation to the complete set increases this quantity, to our best estimate of $9.66 \mathrm{kcal} /$ mol, which is the value displayed in Figure 2. A quick scan of Table 2 illustrates that the MP2/aug-cc-pVDZ interaction energies represent only slight underestimates of the $\operatorname{CCSD}(\mathrm{T}) /$ CBS quantities for all of the dimers. Importantly, the less accurate values obey the same trends, with generally similar energy differences from one dimer to the next.

$\mathrm{NHCHOH}$ replaces one of the $\mathrm{H}$ atoms on the $\mathrm{C}$ of $\mathrm{CH}_{2} \mathrm{NH}$ by an $\mathrm{OH}$ group. The latter is a powerful proton donor so it is no surprise that there is an $\mathrm{OH} \cdots \mathrm{S} \mathrm{HB}$ in the most stable dimer B1 with thiourea (see Figure 3). The strength of this bond is exemplified by the very large $E(2)$ of $25.2 \mathrm{kcal} / \mathrm{mol}$ and the $\rho_{\mathrm{BCP}}$ of 0.0298 au (see Table 1). This geometry is supplemented by a $\mathrm{NH} \cdots \mathrm{O} \mathrm{HB}$, shorter than the $\mathrm{OH} \cdots \mathrm{S} \mathrm{HB}$ but with a slightly smaller $\rho_{\mathrm{BCP}}$ and a much smaller $E(2)$. Together, these two HBs compose a total interaction energy of $13.5 \mathrm{kcal} / \mathrm{mol}$. Both $\mathrm{NH}$ groups of thiourea act as proton donors in B2, with the $\mathrm{NH} \cdots \mathrm{N}$ HB considerably stronger than the $\mathrm{NH} \cdots \mathrm{O}$ HB. This complex is likely disfavored by negative cooperativity because thiourea serve as a double electron acceptor. Only slightly less stable is B3, which combines a strong $\mathrm{NH} \cdots \mathrm{N}$ HB with a weaker $\mathrm{NH} \cdots \mathrm{S}$ HB. This pair of molecules also exhibits a stacking arrangement B4, which is bound by $6.3 \mathrm{kcal} / \mathrm{mol}$. The AIM bonding pattern attributes the stability of $\mathbf{B} 4$ to a single $\mathrm{C} \cdots \mathrm{N}$ interaction, whereas NBO 


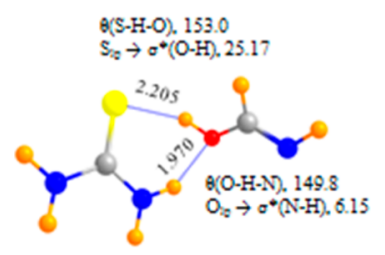

B1, 13.50

B3, 9.96
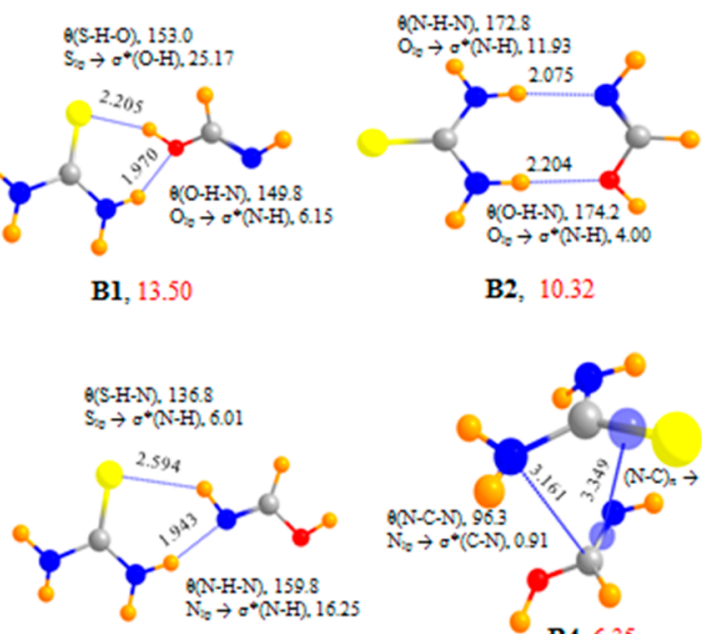

B2, 10.32

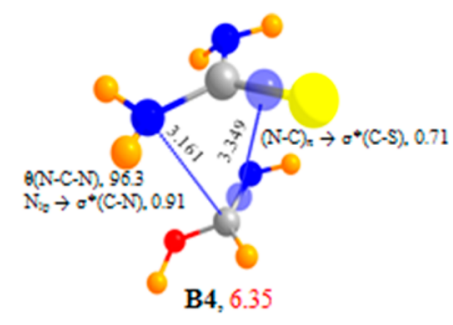

Figure 3. Optimized geometries of complexes of thiourea with $\mathrm{NHCHOH}$. The red number refers to the interaction energy (kilocalories per mole) evaluated at the $\operatorname{CCSD}(\mathrm{T}) / \mathrm{CBS}$ level. Distances are in angstroms and angles in degrees. The NBO value of $E(2)$ is in kilocalories per mole.

indicates a pair of charge transfers in either direction, both involving the imine's $\mathrm{C}-\mathrm{N}$ bond. $\mathbf{B} 3$ is similar to A3, with comparable interaction energies. Examination of Table S1 confirms the earlier pattern that $\operatorname{CCSD}(\mathrm{T})$ interaction energies are slightly larger than MP2/aug-cc-pVDZ quantities but follow similar patterns.

The $\mathrm{OH}$ group in $\mathrm{CH}_{2} \mathrm{NOH}$ leads again to an $\mathrm{OH} \cdots \mathrm{S}$ HB in the global minimum of its dimers with thiourea, as illustrated in Figure 4, and with interaction energies listed in Table S2. Unlike B1, the second $\mathrm{HB}$ in $\mathbf{C 1}$ is of the $\mathrm{NH} \cdots \mathrm{N}$ variety. Even though the latter $\mathrm{HB}$ is quite a bit stronger than the secondary $\mathrm{HB}$ in $\mathbf{B} \mathbf{1}[E(2)=18.7 \mathrm{kcal} / \mathrm{mol}]$, the total interaction energies of these two complexes are quite similar. $\mathbf{C 2}$ is reminiscent of A2, although the strong $\mathrm{NH} \cdots \mathrm{N} \mathrm{HB}$ is $0.1 \AA$ longer in C2 and both $E(2)$ and $\rho_{\mathrm{BCP}}$ are smaller. It is for this reason that the interaction energy is lower in $\mathbf{C 2}$. The pair of $\mathrm{NH} \cdots \mathrm{N}$ HBs to the same imine $\mathrm{N}$ proton acceptor in $\mathrm{C} 3$ is similar to the pattern in A1, although the former is more weakly bound. Note also that the two HBs in $\mathrm{C} 3$ are distinctly different from one another, unlike the symmetric A1 geometry. Although the geometry of $\mathrm{C} 4$ resembles that of $\mathrm{A5}, \mathrm{NBO}$ analysis suggests a pair of $\mathrm{CH}$...S HBs, and not a tetrel bond. AIM, on the other hand, suggests only one of these two HBs. Nonetheless, these two complexes have equal interaction energies. It is interesting to note the absence of a stable stacked dimer for this pair of molecules.

The $\mathrm{OH}$ group of $\mathrm{CH}_{2} \mathrm{NOH}$ is replaced by $\mathrm{NH}_{2}$ in $\mathrm{CH}_{2} \mathrm{NNH}_{2}$, precluding the possibility of an $\mathrm{OH} \cdots \mathrm{S} \mathrm{HB}$. The global minimum D1 in Figure 5 instead contains a pair of $\mathrm{NH} \cdots$ N HBs, with thiourea serving as a double electron acceptor, but to two different, adjacent $\mathrm{N}$ atoms. As indicated in Table S3, this complex is bound by $9.6 \mathrm{kcal} / \mathrm{mol}$, similar to that of $\mathbf{A 1}$ despite the different $\mathrm{HB}$ pattern and the stronger $\mathrm{NH} \cdots \mathrm{N}$ HBs suggested by both NBO and AIM. The pattern of A1 is reproduced instead in $\mathbf{D} 2$, the latter of which is slightly less stable. The $\mathrm{NH} \cdots \mathrm{N} / \mathrm{CH} \cdots \mathrm{S}$ HB pair of $\mathbf{A 2}$ and $\mathbf{C 2}$ arises again in D3, this time with an interaction energy of $8.9 \mathrm{kcal} / \mathrm{mol}$. A new pair of HBs, $\mathrm{NH} \cdots \mathrm{N}$ and $\mathrm{NH} \cdots \mathrm{S}$, occur in D4. It is interesting to note that these four dimers have very similar interaction energies, within $1.2 \mathrm{kcal} / \mathrm{mol}$ of one another. A classic $\mathrm{NH} \cdots \mathrm{N} \mathrm{HB}$ is paired with a $\mathrm{CH} \cdots \pi(\mathrm{CS}) \mathrm{HB}$ in D5. (The latter HB is designated CH...S by AIM.) Both bonds are rather weak, and the total interaction energy is $<5 \mathrm{kcal} / \mathrm{mol}$. The bifurcated arrangement in D6 is quite similar to that in C4, with a comparable interaction energy. The NBO and AIM data agree on the presence of a single $\mathrm{CH} \cdots \mathrm{S}$ HB.

The only prior computational study of complexes between thiourea and an imine ${ }^{41}$ considered $\mathrm{CR}_{2}^{1}{ }_{2} \mathrm{NCR}^{2} \mathrm{O}$, somewhat different from the imines considered here. The geometries of the dimers were optimized at the B3LYP level, with a much smaller $6-31 G^{*}$ basis set. The potential energy surfaces were not examined extensively; instead, only two particular geometries were considered, corresponding roughly to $\mathbf{B} 2$ and $\mathbf{C} 3$. The interaction energies of 4.2 and $4.1 \mathrm{kcal} / \mathrm{mol}$ for $\mathrm{R}^{1}=\mathrm{R}^{2}=$ $\mathrm{H}$ were considerably smaller than our $\operatorname{CCSD}(\mathrm{T}) / \mathrm{CBS}$ values,

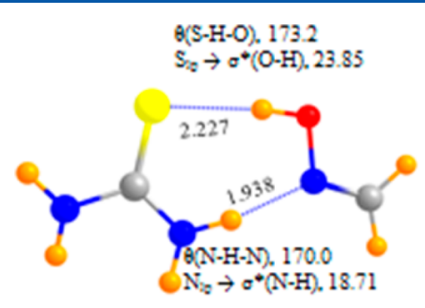

Cl, 13.54

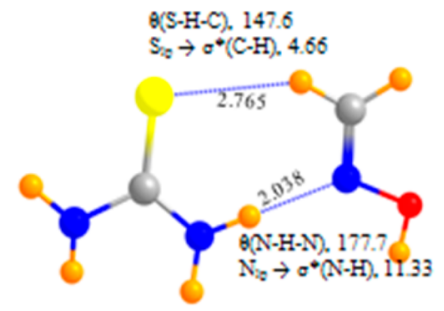

C2, 7.32

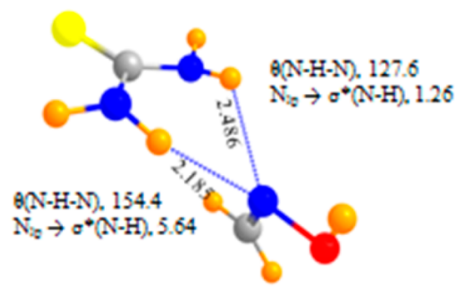

C3, 7.17

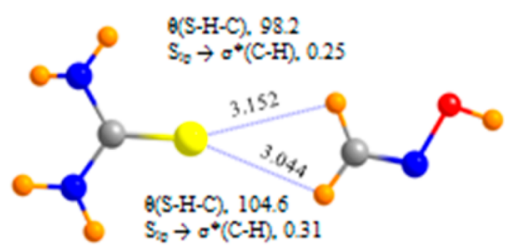

C4, 1.85

Figure 4. Optimized geometries of complexes of thiourea with $\mathrm{CH}_{2} \mathrm{NOH}$. The red number refers to the interaction energy (kilocalories per mole) evaluated at the $\operatorname{CCSD}(\mathrm{T}) / \mathrm{CBS}$ level. Distances are in angstroms and angles in degrees. The NBO value of $E(2)$ is in kilocalories per mole. 


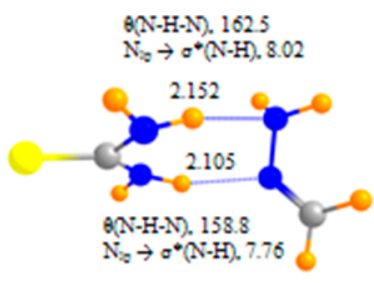

D1, 9.63

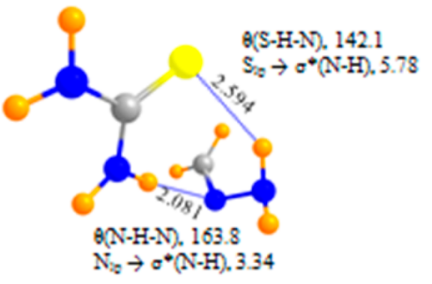

D4, 8.45

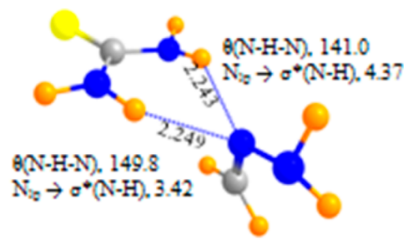

D2, 8.97

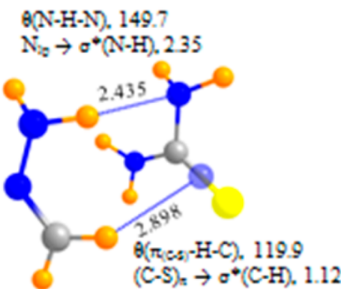

D5, 4.63

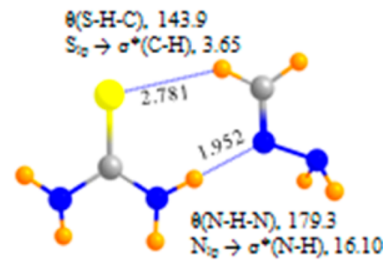

D3, s.ss

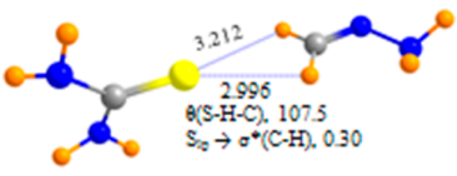

D6, 1.74

Figure 5. Optimized geometries of complexes of thiourea with $\mathrm{CH}_{2} \mathrm{NNH}_{2}$. The red number refers to the interaction energy (kilocalories per mole) evaluated at the $\operatorname{CCSD}(\mathrm{T}) / \mathrm{CBS}$ level. Distances are in angstroms and angles in degrees. The NBO value of $E(2)$ is in kilocalories per mole.

A

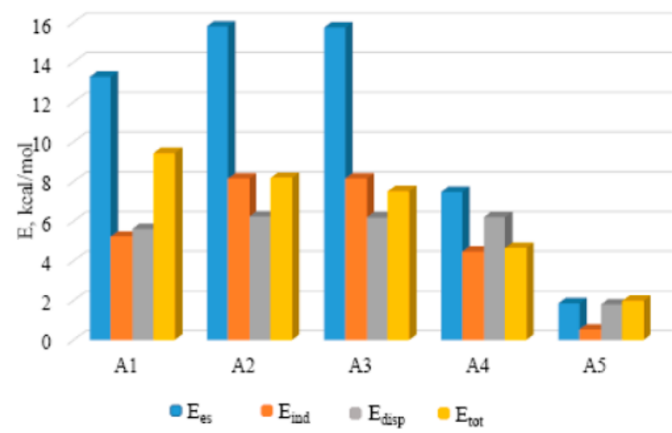

C

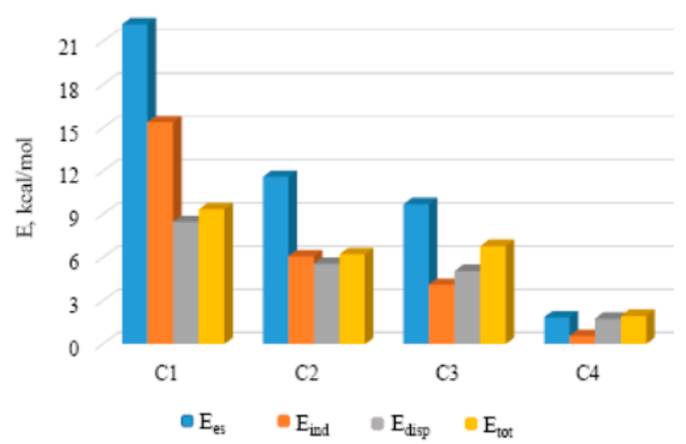

B

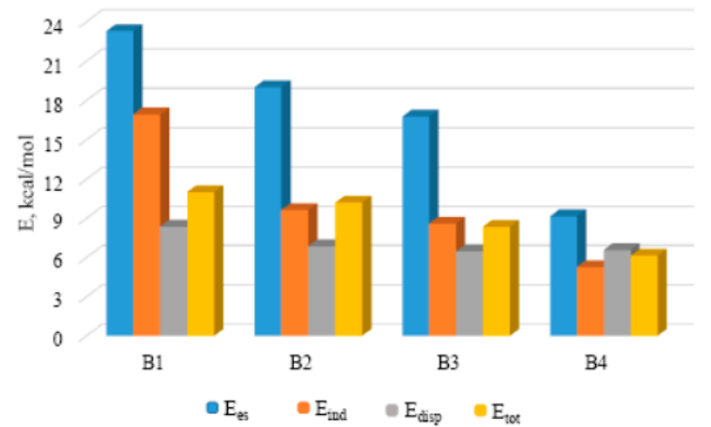

D

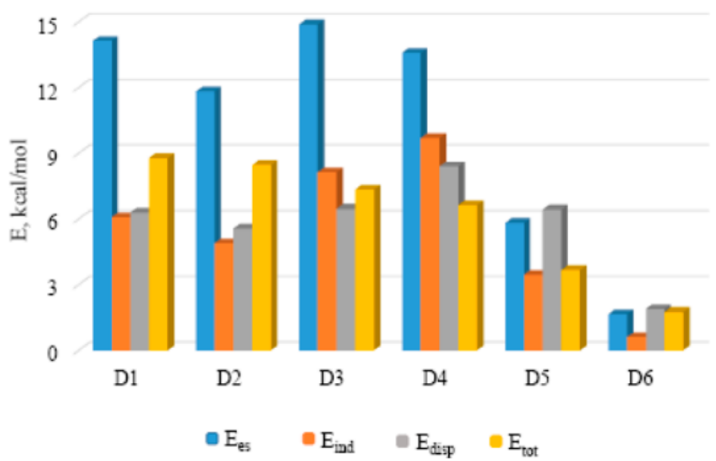

Figure 6. SAPT partitioning of interaction energies in complexes of thiourea with (a) $\mathrm{CH}_{2} \mathrm{NH},\left(\right.$ b) $\mathrm{NHCHOH},(\mathrm{c}) \mathrm{CH}_{2} \mathrm{NOH}_{\text {, and }}(\mathrm{d}) \mathrm{CH}_{2} \mathrm{NNH}_{2}$.

or even our crudest MP2/aug-cc-pVDZ results, for the corresponding structures. It would therefore appear inadvisable to apply small basis sets to systems of this sort.

There have been other computational studies of complexes pairing thiourea with proton acceptors, albeit not imines. An early study involving a water molecule ${ }^{42}$ identified a geometry akin to A1, where both $\mathrm{NH}$ groups of thiourea engage in a $\mathrm{HB}$ with the proton acceptor $\mathrm{O}$. The small basis set found an interaction energy of $<5 \mathrm{kcal} / \mathrm{mol}$. Full-fledged anions of course form stronger complexes ${ }^{43}$ but again show a predilection for a structure like A1. On the other hand, when the anion contains two proton acceptor atoms, as for example in acetate, structures of the $\mathbf{B} 2$ or D1 sort emerge, containing two separate $\mathrm{NH} \cdots \mathrm{X}$ HBs. This same bonding pattern of A1 for a single proton acceptor and $\mathbf{B} 2$ for two acceptor atoms was also noted later ${ }^{44}$ for more complicated systems, and for nitro groups. ${ }^{45}$

Overview. There are several geometrical themes that appear with some regularity. The first type, comprising A1, C3, and D2, has a pair of nearly symmetric $\mathrm{NH} \cdots \mathrm{N} \mathrm{HBs,} \mathrm{with} \mathrm{both} \mathrm{NH}$ groups of thiourea approaching the imine $\mathrm{N}$ from above and 


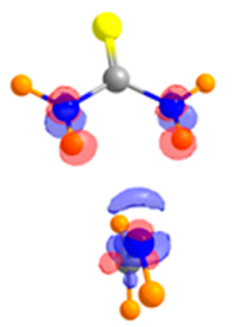

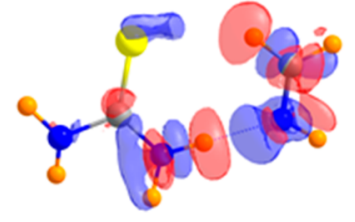

A2

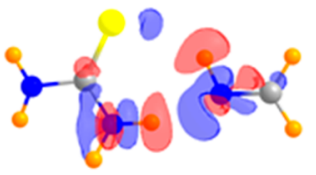

A3

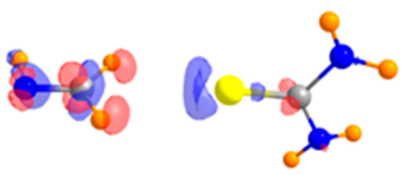

A5

Figure 7. Calculated electron density shifts calculated at MP2/aug-cc-pVDZ level for complexes of thiourea with $\mathrm{CH}_{2} \mathrm{NH}$. Blue and red regions refer to gains and losses of electron density upon complexation, respectively. Contours represent \pm 0.001 au.

below its molecular plane. The presence of either an $\mathrm{OH}$ or $\mathrm{NH}_{2}$ group on the imine reduces the interaction energy from that in A1, presumably by withdrawing electron density from the $\mathrm{N}$ lone pair. A second arrangement combines a linear $\mathrm{NH} \cdots$ $\mathrm{N} \mathrm{HB}$ with a $\mathrm{CH} \cdots \mathrm{S} \mathrm{HB}$, as in the collection of A2, C2, and D3, where the $\mathrm{OH}$ and $\mathrm{NH}_{2}$ groups again weaken the binding. Still another type of geometry is characterized by A5, C4, and D6, in which the $\mathrm{S}$ approaches the imine's $\mathrm{CH}_{2}$ group. All of these are bound by between 1.7 and $1.9 \mathrm{kcal} / \mathrm{mol}$. There is a fine balance between a S...C tetrel bond, as in A5, and bifurcated $\mathrm{CH} \cdots \mathrm{S}$ HBs as in $\mathbf{C 4}$ and D6. There are only two stacked structures, A4 and B4. Their interaction energies are 5.2 and $6.3 \mathrm{kcal} / \mathrm{mol}$, respectively, but their stability rests on different specific interactions. For example, while A4 contains a $\mathrm{NH} \cdots \pi(\mathrm{CS}) \mathrm{HB}, \mathbf{B} 4$ relies on a $\mathrm{N}_{\mathrm{lp}} \rightarrow \sigma^{*}(\mathrm{CN})$ transfer coupled with a back transfer from $\pi(\mathrm{CN})$ to $\sigma^{*}(\mathrm{CS})$.

Energy Partitioning. As another means of analyzing the nature of the interactions in the various heterodimers, the total interaction energy was dissected into its components. SAPT calculations were conducted at the HF/aug-cc-pVDZ level of theory. The contributions of each of the attractive components are illustrated in Figure 6. In most cases, particularly where the interaction is primarily of the $\mathrm{HB}$ type, the electrostatic attraction represents the largest contribution, exceeding 20 $\mathrm{kcal} / \mathrm{mol}$ in certain cases. Induction and dispersion are smaller, and comparable to one another. The exceptions to this behavior are observed in the stacked structures and those containing a tetrel bond, i.e., A4, A5, B4, C4, D5, and D6. In these cases, the electrostatic contribution is reduced and dispersion makes a much larger percentage contribution, comparable to or even exceeding ES. The sum of all of the components including exchange repulsion yields the total interaction energy, shown as the yellow bar in Figure 6. This SAPT sum matched rather closely with the $\operatorname{CCSD}(\mathrm{T}) /$ aug-ccpVDZ quantity, with a correlation coefficient of 0.94 .

Electron Density Shifts. The formation of any molecular interaction causes the electron density to shift, both internal within each molecule and externally from one molecule to the other. Each sort of noncovalent bond manifests itself in a characteristic shift, a fingerprint if you will. These shifts are displayed in Figure 7 for the complexes of urea with $\mathrm{CH}_{2} \mathrm{NH}$. Each was generated by subtracting the densities of the individual isolated monomers from that of the entire complex.
Blue regions designate an area in which density is gained as a result of the formation of the complex, and losses are shown in red.

The pattern illustrated for complex A1 fits into the classic picture of HBs. Density is lost around the bridging protons and is acquired in the region of the lone pair of the protonaccepting atom, with additional gain seen in the vicinity of the proton-donating atom. This same pattern is evident in the HBs of structures A2 and A3. Although NBO suggests the interaction in $\mathrm{A5}$ is best described as a S...C tetrel bond, the prominent red losses around the two $\mathrm{CH}$ protons, and the blue gain near the $S$ atom, might argue instead for a bifurcated $H B$, consistent with AIM data. The pattern for stacked configuration A4 is perhaps a bit more complicated. It confirms the presence of a NH...S HB as suggested by AIM, although NBO places the source of the density as the CS $\pi$ bond, not obvious in Figure 7 . There is also little direct evidence of transfer from $\pi(\mathrm{CN})$ to $\sigma^{*}(\mathrm{CS})$ as predicted by NBO.

The electron density shifts of the $\mathbf{B}, \mathbf{C}$, and $\mathbf{D}$ complexes are displayed in the Supporting Information (Figures S1-S3). As for the A structures, HBs exhibit the same characteristic pattern. The B4 structure is particularly interesting. NBO describes charge transfers from the imine NC $\pi$-bond to the thiourea CS $\sigma^{*}$ antibond, which is not easily seen in the density shift. Nor is the NBO transfer in the reverse direction from the thiourea $\mathrm{N}$ lone pair to the $\mathrm{CN} \sigma^{*}$ antibond readily apparent. The AIM prediction of a $\mathrm{C} \cdots \mathrm{N}$ bond path is similarly not confirmed in the density shift pattern. With this exception, though, the density shift patterns are entirely consistent with the NBO and AIM interpretations of bonding.

Effect of Complexation on Imine Geometry. It is reasonable to suppose that one of the most important effects of the thiourea catalyst upon the imine might be to prepare it for reaction, perhaps by affecting the strength of the $\mathrm{C}-\mathrm{N}$ bond. One measure of this bond strength is the length of this bond. Table 3 displays the change undergone by this bond, in units of milliangstroms, within the context of each dimer. With the $\mathbf{A}$ dimers with $\mathrm{CH}_{2} \mathrm{NH}$ as an example, the $\mathrm{C}-\mathrm{N}$ bond stretches between 1 and $2 \mathrm{~mA}$ for all structures with the exception of A3, where the bond contracts by $2.5 \mathrm{~m} \AA$. A similar contraction occurs in B3. What these two geometries share in common, differing from all other dimers, is the participation of the imine $\mathrm{NH}$ in a $\mathrm{HB}$. 
Table 3. Changes in $\mathrm{C}-\mathrm{N}$ Bond Lengths of Imines (milliangstroms) Caused by the Formation of the Indicated Heterodimer

\begin{tabular}{rrrrr} 
& A & B & \multicolumn{1}{c}{ C } & \multicolumn{1}{c}{ D } \\
$\mathbf{1}$ & 2.2 & 4.0 & 1.9 & -0.7 \\
$\mathbf{2}$ & 2.1 & 0.2 & -0.7 & 2.3 \\
$\mathbf{3}$ & -2.5 & -2.7 & 0.8 & -4.2 \\
$\mathbf{4}$ & 1.2 & 1.5 & -0.3 & 4.8 \\
$\mathbf{5}$ & 1.0 & & & 2.9 \\
$\mathbf{6}$ & & & & 0.0 \\
\hline
\end{tabular}

Another configuration that suffers a significant contraction of the $\mathrm{C}-\mathrm{N}$ bond length is $\mathrm{D} 3$. This structure combines a strong $\mathrm{NH} \cdots \mathrm{N}$ HB to the imine $\mathrm{N}$ proton acceptor with a $\mathrm{CH} \cdots \mathrm{S} \mathrm{HB}$. This same motif occurs as well in A2 and C2. The latter shows a small $\mathrm{C}-\mathrm{N}$ bond contraction; however, the former undergoes a bond lengthening, so this particular combination of HBs cannot be considered as universally shrinking the $\mathrm{C}-\mathrm{N}$ bond.

In summary, most of the complexes produce a lengthening of the $\mathrm{C}-\mathrm{N}$ bond, particularly the most strongly bound. In many, but not all of these, the imine $\mathrm{N}$ acts as proton acceptor. If, on the other hand, the imine $\mathrm{CH}$ simultaneously acts as proton donor, there is a tendency for this rule to be reversed. Participation of the imine $\mathrm{NH}$ also has a tendency to shorten the $\mathrm{C}-\mathrm{N}$ bond, but we stress that these are only general rules, with several exceptions noted.

\section{DISCUSSION}

There are a wide range of different geometries when thiourea combines with each sort of substituted imine. The most strongly bound of these contain one or more HBs. One type is characterized by a pair of nearly symmetric $\mathrm{NH} \cdots \mathrm{N}$ HBs, with both $\mathrm{NH}$ groups of thiourea approaching the imine $\mathrm{N}$ from above and below its molecular plane. Another arrangement combines a linear $\mathrm{NH} \cdots \mathrm{N}$ HB with a $\mathrm{CH} \cdots \mathrm{S}$ HB. The sulfur atom approaches the imine's $\mathrm{CH}_{2}$ group in a third category, which is supplemented by a stacked arrangement in a fourth. The interaction energies vary from as little as $2 \mathrm{kcal} / \mathrm{mol}$ for the structures containing a bifurcated $\mathrm{CH}_{2} \cdots \mathrm{S} \mathrm{HB}$ to a maximum of $13.5 \mathrm{kcal} / \mathrm{mol}$ for the $\mathrm{NHCHOH}$ imine that combines a pair of $\mathrm{NH} \cdots \mathrm{O}$ and $\mathrm{OH} \cdots \mathrm{S}$ HBs.

In most cases, particularly when the interaction is primarily of the HB type, the electrostatic attraction makes the largest contribution to the binding, with induction and dispersion comparable to one another. In the stacked structures and those containing a tetrel bond, on the other hand, the electrostatic contribution is reduced and dispersion makes a much larger percentage contribution. Electron density shift patterns are consistent with the formulation of the interaction on the basis of HBs. The formation of the complex typically elongates the imine $\mathrm{C}-\mathrm{N}$ bond by $0.001-0.004 \AA$, but there are certain arrangements wherein this bond is contracted.

Of the various imines examined here, one of them $(\mathrm{NHCHOH})$ has available to it more than a single geometry. That is, the configuration examined and illustrated in Figure 3 has both the $\mathrm{NH}$ and $\mathrm{OH}$ hydrogen atoms cis to the $\mathrm{CH}$, but either of these could also be trans to the $\mathrm{CH}$, which could conceivably alter some of the trends discussed above. To determine whether any such reversal might occur, a full set of calculations was conducted for the structure wherein the $\mathrm{NH}$ group is rotated around to lie trans to the $\mathrm{CH}$. The five minima identified in the complex of this variant of $\mathrm{NHCHOH}$ are illustrated in Figure S4. The binding themes were found to be quite similar to those of the all-cis isomer in Figure 3, and indeed of all of the imines. The global minimum E1 is like B1, again one in which an $\mathrm{OH} \cdots \mathrm{S} \mathrm{HB}$ is supplemented by a $\mathrm{NH} \cdots \mathrm{O}$ interaction, with a very similar interaction energy. The second minimum contains a $\mathrm{NH} \cdots \mathrm{N} / \mathrm{CH} \cdots \mathrm{S} \mathrm{HB}$ pair, just as in $\mathbf{A 2}$, C2, and D3. E3 contains a pair of bifurcated $\mathrm{NH} \cdots \mathrm{N}$ HBs, quite similar to A1. Further reinforcing the similarities, SAPT decomposition of the interaction energies of these five $\mathrm{E}$ structures reveals nearly identical patterns as is evident in Figure 6, and electron density shifts mimic those of the other imines.

Finally, as was mentioned earlier, interaction energies have all been corrected for basis set superposition error. The counterpoise corrections are rather small, all $<0.6 \mathrm{kcal} / \mathrm{mol}$, some as small as $0.2 \mathrm{kcal} / \mathrm{mol}$ at the MP2/aug-cc-pVQZ level. On a percentage basis, these corrections amount to $<5 \%$ in most cases.

\section{ASSOCIATED CONTENT}

\section{S Supporting Information}

The Supporting Information is available free of charge on the ACS Publications website at DOI: 10.1021/acs.joc.5b01985.

Electron density shifts, optimized geometries of $\mathrm{NHCHOH}$ ( $\mathrm{NH}$ trans to $\mathrm{CH}$ ), energetic data, and atomic coordinates of optimized structures (PDF)

\section{AUTHOR INFORMATION}

\section{Corresponding Author}

*E-mail: steve.scheiner@usu.edu.

\section{Notes}

The authors declare no competing financial interest.

\section{ACKNOWLEDGMENTS}

Computer, storage, and other resources from the Division of Research Computing in the Office of Research and Graduate Studies at Utah State University are gratefully acknowledged.

\section{REFERENCES}

(1) Dalko, P. I.; Moisan, L. Angew. Chem., Int. Ed. 2004, 43, 5138.

(2) Seayad, J.; List, B. Org. Biomol. Chem. 2005, 3, 719.

(3) Dalko, P. I. In Enantioselective Organocatalysis Reactions and Experimental Procedure; Dalko, P. I., Ed.; Wiley-VCH: Weinheim, Germany, 2007.

(4) Mukherjee, S.; Yang, J. W.; Hoffmann, S.; List, B. Chem. Rev. 2007, 107, 5471.

(5) MacMillan, D. W. C. Nature 2008, 455, 304.

(6) Francis, M. B.; Finney, N. S.; Jacobsen, E. N. J. Am. Chem. Soc. 1996, 118, 8983.

(7) Sigman, M. S.; Jacobsen, E. N. J. Am. Chem. Soc. 1998, 120, 4901.

(8) Sigman, M. S.; Vachal, P.; Jacobsen, E. N. Angew. Chem., Int. Ed. 2000, 39, 1279.

(9) Vachal, P.; Jacobsen, E. N. Org. Lett. 2000, 2, 867.

(10) Yoon, T. P.; Jacobsen, E. N. Angew. Chem., Int. Ed. 2005, 44, 466.

(11) Okino, T.; Nakamura, S.; Furukawa, T.; Takemoto, Y. Org. Lett. 2004, 6, 625.

(12) Taylor, M. S.; Jacobsen, E. N. J. Am. Chem. Soc. 2004, 126, 10558.

(13) Esrafili, M. D.; Mohammadian-Sabet, F. Chem. Phys. Lett. 2015, 634, 210.

(14) Azofra, L. M.; Alkorta, I.; Scheiner, S. J. Phys. Chem. A 2015, $119,535$.

(15) Zhou, F.; Liu, R.; Li, P.; Zhang, H. New J. Chem. 2015, 39, 1611. 
(16) Fanfrlík, J.; Přáda, A.; Padělková, Z.; Pecina, A.; Macháček, J.; Lepšík, M.; Holub, J.; Růžička, A.; Hnyk, D.; Hobza, P. Angew. Chem., Int. Ed. 2014, 53, 10139.

(17) Desiraju, G. R.; Nalini, V. J. Mater. Chem. 1991, 1, 201.

(18) Iwaoka, M.; Takemoto, S.; Tomoda, S. J. Am. Chem. Soc. 2002, $124,10613$.

(19) Nziko, V. d. P. N.; Scheiner, S. J. Phys. Chem. A 2015, 119, 5889.

(20) Werz, D. B.; Gleiter, R.; Rominger, F. J. Am. Chem. Soc. 2002, $124,10638$.

(21) Sanz, P.; Mó, O.; Yáñez, M. Phys. Chem. Chem. Phys. 2003, 5, 2942.

(22) Cozzolino, A. F.; Vargas-Baca, I.; Mansour, S.; Mahmoudkhani, A. H. J. Am. Chem. Soc. 2005, 127, 3184.

(23) Nziko, V. d. P. N.; Scheiner, S. J. Org. Chem. 2015, 80, 2356.

(24) Bleiholder, C.; Werz, D. B.; Koppel, H.; Gleiter, R. J. Am. Chem. Soc. 2006, 128, 2666.

(25) Gleiter, R.; Werz, D. B.; Rausch, B. J. Chem.—Eur. J. 2003, 9, 2676.

(26) Nziko, V. d. P. N.; Scheiner, S. J. Phys. Chem. A 2014, 118, 10849 .

(27) Sánchez-Sanz, G.; Alkorta, I.; Elguero, J. Mol. Phys. 2011, 109, 2543.

(28) Wu, C. H.; Ramamoorthy, A.; Gierasch, L. M.; Opella, S. J. J. Am. Chem. Soc. 1995, 117, 6148.

(29) Frisch, M. J.; Trucks, G. W.; Schlegel, H. B.; Scuseria, G. E.; Robb, M. A.; Cheeseman, J. R.; Scalmani, G.; Barone, V.; Mennucci, B.; Petersson, G. A.; Nakatsuji, H.; Caricato, M.; Li, X.; Hratchian, H. P.; Izmaylov, A. F.; Bloino, J.; Zheng, G.; Sonnenberg, J. L.; Hada, M.; Ehara, M.; Toyota, K.; Fukuda, R.; Hasegawa, J.; Ishida, M.; Nakajima, T.; Honda, Y.; Kitao, O.; Nakai, H.; Vreven, T.; Montgomery, J. A., Jr.; Peralta, J. E.; Ogliaro, F.; Bearpark, M.; Heyd, J. J.; Brothers, E.; Kudin, K. N.; Staroverov, V. N.; Kobayashi, R.; Normand, J.; Raghavachari, K.; Rendell, A.; Burant, J. C.; Iyengar, S. S.; Tomasi, J.; Cossi, M.; Rega, N.; Millam, J. M.; Klene, M.; Knox, J. E.; Cross, J. B.; Bakken, V.; Adamo, C.; Jaramillo, J.; Gomperts, R.; Stratmann, R. E.; Yazyev, O.; Austin, A. J.; Cammi, R.; Pomelli, C.; Ochterski, J. W.; Martin, R. L.; Morokuma, K.; Zakrzewski, V. G.; Voth, G. A.; Salvador, P.; Dannenberg, J. J.; Dapprich, S.; Daniels, A. D.; Farkas, O.; Foresman, J. B.; Ortiz, J. V.; Cioslowski, J.; Fox, D. J. Gaussian 09, revision B.01; Gaussian, Inc.: Wallingford, CT, 2009.

(30) Boys, S. F.; Bernardi, F. Mol. Phys. 1970, 19, 553.

(31) Helgaker, T.; Klopper, W.; Koch, H.; Noga, J. J. Chem. Phys. 1997, 106, 9639.

(32) Mishra, B. K.; Karthikeyan, S.; Ramanathan, V. J. Chem. Theory Comput. 2012, 8, 1935.

(33) Szalewicz, K.; Jeziorski, B. Symmetry-adapted perturbation theory of intermolecular interactions. In Molecular Interactions. From Van der Waals to Strongly Bound Complexes; Scheiner, S., Ed.; Wiley: New York, 1997; pp 3.

(34) Moszynski, R.; Wormer, P. E. S.; Jeziorski, B.; van der Avoird, A. J. Chem. Phys. 1995, 103, 8058.

(35) Werner, H.-J.; Knowles, P. J.; Manby, F. R.; Schütz, M.; Celani, P.; Knizia, G.; Korona, T.; Lindh, R; Mitrushenkov, A.; Rauhut, G.; Adler, T. B.; Amos, R. D.; Bernhardsson, A.; Berning, A.; Cooper, D. L.; Deegan, M. J. O.; Dobbyn, A. J.; Eckert, F.; Goll, E.; Hampel, C.; Hesselmann, A.; Hetzer, G.; Hrenar, T.; Jansen, G.; Köppl, C.; Liu, Y.; Lloyd, A. W.; Mata, R. A.; May, A. J.; McNicholas, S. J.; Meyer, W.; Mura, M. E.; Nicklaß, A.; Palmieri, P.; Pflüger, K.; Pitzer, R.; Reiher, M.; Shiozaki, T.; Stoll, H.; Stone, A. J.; Tarroni, R.; Thorsteinsson, T.; Wang, M.; Wolf, A. MOLPRO, version 2006; 2010.

(36) Reed, A. E.; Weinhold, F.; Curtiss, L. A.; Pochatko, D. J. J. Chem. Phys. 1986, 84, 5687.

(37) Reed, A. E.; Curtiss, L. A.; Weinhold, F. Chem. Rev. 1988, 88, 899.

(38) Bader, R. F. W. Atoms in Molecules, a Quantum Theory; Clarendon Press: Oxford, U.K., 1990; Vol. 22, p 438.

(39) Carroll, M. T.; Chang, C.; Bader, M. F. W. Mol. Phys. 1988, 63, 387.
(40) Keith, T. A. AIMALL; TK Gristmill Software: Overland Park, KS, 2013.

(41) Zheng, W.-R.; Fu, Y.; Shen, K.; Liu, L.; Guo, Q.-X. J. Mol. Struct.: THEOCHEM 2007, 822, 103.

(42) Weiqun, Z.; Wen, Y.; Lihua, Q. J. Mol. Struct.: THEOCHEM 2005, 730, 133.

(43) Jose, D. A.; Singh, A.; Das, A.; Ganguly, B. Tetrahedron Lett. 2007, 48, 3695 .

(44) Fleming, E. M.; Quigley, C.; Rozas, I.; Connon, S. J. J. Org. Chem. 2008, 73, 948.

(45) Zheng, W.; Xu, J.; Huang, T.; Yang, Q.; Chen, Z. Res. Chem. Intermed. 2011, 37, 31. 